\title{
Fracture toughness and thermal shock of tool and turbine ceramics
}

\author{
Y. W. MAI, A. G. ATKINS* \\ Department of Mechanical Engineering, University of Michigan, Ann Arbor, Michigan, \\ USA
}

The behaviour of some commercial tool carbides and turbine ceramics has been investigated in regard to resistance to crack initiation, crack propagation and retained strength after thermal shock. New data are provided, particularly measurements of the fracture toughness of these materials at actual operating temperatures (up to $1200^{\circ} \mathrm{C}$ ). Many of the materials did not follow the generally accepted Hasselman theory for thermal shock in ceramics, and instead of showing a discontinuity in retained strength at some critical quenching temperature difference, their residual strengths fell gradually at temperatures lower than their supposed critical quenching temperature. This behaviour is explicable when high temperature toughnesses, strengths and moduli are used in the damage resistance parameter $\left(E R / \sigma_{f}^{2}\right)$. It seems that materials not following the Hasselman model suffer cumulative damage with increasing number of shocks. Sub-critical crack growth occurs even if $\left(K_{\mathrm{IC}} / \sigma_{\mathrm{f}}\right)^{2}$ values are constant, and such damage, which reduces the room temperature retained strength, is enhanced by $\left(K_{\mathrm{IC}} / \sigma_{\mathrm{f}}\right)^{2}$ decreasing at temperatures below $\Delta T_{c}$. In contrast, materials obeying Hasselman's model appear to have a constant $\left(K_{\mathrm{Ic}} / \sigma_{\mathrm{f}}\right)^{2}$ below $\Delta T_{\mathrm{c}}$ and for some temperature range above. Only then are "one-shock" characterizations of materials possible, otherwise, the retained strength depends upon the number of prior shocks. Experiments are also reported which describe the effects of rate of testing on the unshocked and shocked mechanical properties of ceramics. Oxidation is shown to influence the results in a manner not obvious from single shock tests.

\section{List of symbols}

$\alpha \quad$ Linear thermal expansion coefficient

$h \quad$ Heat transfer coefficient

$k \quad$ Thermal conductivity

$\sigma_{\mathrm{f}} \quad$ Tensile fracture strength

$\sigma_{\mathbf{T}} \quad$ Thermal shock induced tensile stress

$\sigma_{\mathrm{a}} \quad$ Retained strength of thermally shocked testpiece

$E \quad$ Young's modulus

$E_{0} \quad$ Young's modulus of crack-free material

$\nu \quad$ Poisson's ratio

$B \quad$ Biot modulus $=a h / k$

$a$ Half thickness, or radius of thermal shocked body

$\Delta T_{\mathrm{c}} \quad$ Critical shock temperature difference $r_{0}, r_{\mathrm{f}}$ Radius of circular flaws. Subscripts 0 and $\mathrm{f}$ refer to initial and final conditions

$N \quad$ Crack density

$R^{*}, R$ Fracture surface energies (fracture toughness)

$V \quad$ Volume of material under strain

$P \quad$ Load

$u \quad$ Displacement

$K_{\text {IC }} \quad$ Critical stress intensity factor for mode I fracture

$\dot{L} \quad$ Crack velocity

$N_{\mathbf{f}} \quad$ Number of thermal cycles to failure

\section{Introduction}

Ceramics very often fail in service because

\footnotetext{
* Present address: Delta Materials Research Ltd, Box 22, Hedleigh Road, Ipswich, Suffolk, UK.
} 
fractures induced by thermal shocks either break the part in one go, or degrade the retained strength cumulatively. Although many studies have been made of thermal shock fractures in refractories [1-2] and oxides of ceramics [3-5], only limited research has been published on the thermal shock behaviour of those ceramics commonly used for cutting tools and as turbine materials. The present paper concerns these latter two types of ceramic.

One traditional type of thermal shock test consists in successively plunging a small specimen a number of times from some high temperature into a cold fluid and then looking for surface cracks. The temperature from which the quenchings take place is increased and the process repeated until cracks are observed. The final temperature at which cracks are initiated is used to rank materials for given geometries and environments (i.e. quenching media). The type and size of specimen, and the heating and quenching schedules, vary from worker to worker and are arbitrary. Such tests are sometimes continued at increasing temperature intervals until the already initiated cracks propagate in shock so that the specimens break completely. Then, in addition to the merit ranking based upon crack initiation, some idea of the life of the part is available by adding up the total number of heating and quenching cycles to failure. Insofar as the heating and quenching schedules are arbitrary, the results are quite empirical.

Another type of thermal shock evaluation measures the room temperature strength that testpieces (usually three-point bend specimens) retain after they have been shocked. Such experiments are used particularly to investigate the Hasselman theory $[3,4]$ of thermal shock.

A generalized theory of thermal-shock-induced failure has been developed by Hasselman, in which both aspects of crack initiation and propagation are covered [3]. A body is considered to have many mechanical flaws in the form of penny shaped Griffith microcracks of radius $r_{0}$. There are $N /$ unit volume. The body is presumed to undergo a given thermal shock rapid temperature change with mild heat transfer conditions (i.e. the Biot modulus, $B=a h / k$, is small). The critical stress to cause crack initiation is given by:

$$
\sigma_{\mathrm{f}}=\frac{\pi}{2} \sqrt{[}\left[\frac{E_{0} R}{\pi r_{0}\left(1-\nu^{2}\right)}\right] \text {. }
$$

By considering the potential energy of the body at crack initiation, together with the maximum thermal stress induced by a given thermal shock, it is possible to predict that a critical shock temperature difference $\left(\Delta T_{\mathrm{c}}\right)$ is required to initiate all $N$ cracks, where

$$
\begin{gathered}
\Delta T_{\mathrm{c}} \geqslant \frac{1.625}{\alpha} \frac{k}{a h} \sqrt{\left[\frac{\pi R(1-\nu)}{r_{0} E_{0}(1+\nu)}\right]} \\
{\left[1+\frac{16 r_{0}^{3}\left(1-\nu^{2}\right) N}{3}\right] .}
\end{gathered}
$$

It is seen that $\Delta T_{\mathbf{c}}$ for crack initiation is proportional to $k \sigma_{\mathbf{f}} /(\alpha E)$ a fact which may be deduced also from simple considerations of thermal stresses in crack-free bodies $[6,7]$. Notice that for long cracks $\Delta T_{\mathrm{c}}$ also increases with $N$.

The events subsequent to crack initiation either may involve catastrophic propagation giving complete rupture, or may involve crack arrest after some propagation, where excess energy at initiation (converted into crack kinetic energy), is ultimately absorbed by the body so that the cracks arrest. If all $N$ penny cracks grow from $r_{0}$ to an arrested radii $r_{f}$, it may be shown that [3]

$$
r_{\mathrm{f}}=\frac{1}{2 \sqrt{ } 2}\left[\frac{R / R^{*}}{N r_{0}\left(1-\nu^{2}\right)}\right]^{1 / 2}
$$

for $r_{\mathrm{f}} \gg r_{0}$, thus

$$
\begin{aligned}
r_{\mathrm{f}} & =\sqrt{ }\left(\frac{1}{2 \pi N}\right) \cdot\left(\frac{E_{0} R^{*}}{\sigma_{\mathrm{f}}^{2}}\right)^{-1 / 2} \\
& =\sqrt{\left[\frac{1}{2 \pi N\left(1-\nu^{2}\right)}\right]\left(\frac{K_{\mathrm{IC}}}{\sigma_{\mathrm{f}}}\right)^{-1}}
\end{aligned}
$$

using Equation 1. $r_{\mathbf{f}}$ indicates the damage or extent of crack propagation, so that materials in which $r_{f}$ is kept small have good thermal shock damage resistance. In this way, large $\left(E R^{*} / \sigma_{\mathrm{f}}^{2}\right)=\left(K_{\mathrm{IC}} /\right.$ $\left.\sigma_{\mathrm{f}}\right)^{2} \cdot\left(1-\nu^{2}\right)^{\dagger}$ and large $N$ promote thermal shock resistance. Notice that $R^{*}$ (the average dynamic work of fracture in the shock environment) is not necessarily the same as $R$ for initiation; in the absence of precise values, it is, however, customary to assume that $R^{*}=R$.

Subsequent room temperature testing of materials shocked above $\Delta T_{\mathbf{c}}$ show a degraded strength as the fracture loads are those to break testpieces containing larger $r_{\mathrm{f}}$ cracks rather than

$\dagger E R^{*} / \sigma_{f}^{2}$ or $\left(K_{\mathrm{IC}} / \sigma_{\mathrm{f}}\right)^{2}$ in fracture mechanics describes the size of the plastic zone at the crack tip [8]. Recent research shows also that the group characterizes the transition of quasi-static cracking to generalized yielding [9], and that it can rank the machinability of materials [10]. 


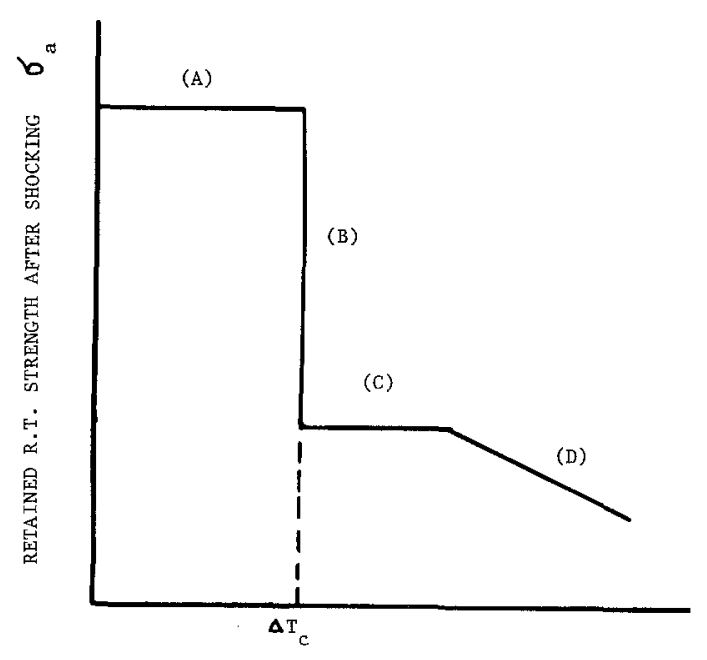

THERMAL SHOCK TEMPERATURE DIFFERENCE

Figure 1 Schematic representation of strength behaviour versus thermal shock severity (after Hasselman [31]. (A) Constant "as-received" strength, no fracture initiation caused by shock. (B) Instantaneous decreases in strength (crack propagation and arrest). (C) Constant strength (previously arrested cracks now sub-critical for these $\Delta T$ ). (D) Gradual decrease in strength as cracks get longer.

smaller $r_{0}$ cracks. Fig. 1 shows schematically the after-shock strength behaviour against the shock severity according to the Hasselman theory. It should be noted that only single shocks (as opposed to a number of repeated shocks from a given temperature) are necessary to characterize a material obeying this model since short initial flaws, once initiated by the critical temperature difference, spread quickly to larger arrested cracks which are then "sub-critical" until very much larger thermal shock temperature differences. Thus, the retained strength after shocks bigger than $\Delta T_{\mathrm{c}}$ for some range is constant (region $\mathrm{C}$ ), since the arrested $r_{\mathrm{f}}$ cracks are sub-critical for additional propagation in this range of temperature. It may be shown [11] that the fractional retained strength of a rectangular beam, after the critical shock is approximately given by:

$$
\frac{\sigma_{\mathrm{a}}}{\sigma_{\mathrm{f}}}=\left[\frac{1.28}{\pi} \frac{N E^{2} R^{2} E_{0} R^{*}}{\left(1-v^{2}\right)^{2} \sigma_{\mathrm{f}}^{6}}\right]^{1 / 4} .
$$

If it be assumed that $E_{0}=E$ and $R^{*}=R$, we have

$$
\sigma_{\mathrm{a}} / \sigma_{\mathrm{f}} \propto N^{1 / 4}\left(K_{\mathrm{IC}} / \sigma_{\mathrm{f}}\right)^{3 / 2}
$$

so that the strength loss $\left(\sigma_{\mathrm{f}}-\sigma_{\mathrm{a}}\right) / \sigma_{\mathrm{f}}$ may be correlated with $\left(K_{\mathrm{IC}} / \sigma_{\mathrm{f}}\right)^{2}$.

Experiments in support of the model may be found in Hasselman [4], Davidge and Tappin [12] and Gupta [5] for single crystal sapphire and for polycrystalline $\mathrm{Al}_{2} \mathrm{O}_{3}$ of various grain sizes; in Gupta [13] for a hot-pressed $\mathrm{ZnO}$; and in Coppola et al. [14] for aluminosilicate and soda-lime glass. It should be noted that magnitudes of the controlling parameters, such as $E R^{*} / \sigma_{\mathrm{f}}^{2}$ or $\left(K_{\mathrm{IC}} / \sigma_{\mathrm{f}}\right)^{2}$ etc, in these studies have been worked out using room temperature values of the modulus, toughness and strength. High temperature values are often not known, but as will be demonstrated later in this paper, variations in $E, R$ or $\sigma_{\mathrm{f}}$ with temperature, affect the response of materials to shock, and lead to marked deviations from the Hasselman model.

Not all ceramics precisely follow the Hasselman model. For example, Ainsworth and Herron [2] have shown that after-shock strength loss of steel-works refractories depends on the number of shocks, the retained strength levelling off only after some 10 to 15 cycles; the model suggests that one shock from the critical level should do all the damage. In the experiments reported in this paper, we find that repeated shocks at a constant quenching temperature difference cause cumulative strength degradation, when compared with a single shock. The strength retained after shock is proportional to the onefourth power of crack density (Equation 6). Experiments show that the crack density usually increases with the quenching temperature difference and the number of shocks (see for example the study [15] on polycrystalline $\mathrm{Al}_{2} \mathrm{O}_{3}$ ). At more severe shocks, some cracks will coalesce during spreading thus reducing the crack density and increasing the average crack length. The combined result must be to produce reductions in predicted strength.

The present work also shows that not all ceramics show an instantaneous strength degradation at a critical $\Delta T_{\mathrm{c}}$. Some materials show a gradual reduction in retained strength at increasing shock temperature differences. Explanations for this behaviour may be given, however, if due account is taken of temperature (and possible rate) variations in modulus, strength and fracture toughness. Oxidation also influences retained strength as will be shown.

This paper, therefore, presents new data not only on the thermal shock behaviour of some tool and turbine ceramics, but also on other mechanical property variations with temperarure and rate particularly fracture toughness. Sensible overall interpretations follow by using such data in the thermal shock analysis. 


\section{Experiments}

\subsection{Materials}

The ceramics studied may be divided into two groups, namely those used in turbine applications (M19, magnesium-aluminium-silicate, 2MgO2 $\mathrm{Al}_{2} \mathrm{O}_{3} 5 \mathrm{~S}_{\mathrm{i}} \mathrm{O}_{2}$; Owens Illinois "Cer Vit" (Registered Name) $\mathrm{C} 140$ and C132, lithium-aluminiumsilicates), and those used in cutting (Nippon A2, a hot-pressed alumina mixed with titanium carbide, $70 \mathrm{Al}_{2} \mathrm{O}_{3} 30 \mathrm{TiC}$ percent; Adamas Co. Titan 60 and Titan 80 , both titanium carbides with $\mathrm{Ni}-\mathrm{Mo}$ binder; Kennametal K96, a tungsten carbide with cobalt binder; and two lots of GE Carboloy 370, a tungsten carbide blended with cobalt, $\mathrm{WC} / \mathrm{TiC} /$ $\mathrm{TaC} / \mathrm{Co}, 72 / 8 / 11.3 / 8.5 \%$ by weight, one dense commercial tool material, the other a specially made up lower density material).

For various reasons, the materials were used in various sizes and shapes, some specially prepared, some directly in the as-bought commercial tool insert size and shape. Because of the difficulty of obtaining large pieces of these solids, much thought was given to the best use of the available samples, and suggestions are given later regarding fracture toughness testpieces.

\subsection{Thermal shock tests}

Specimens with dimensions $12.7 \mathrm{~mm} \times 12.7 \mathrm{~mm} \times$ $4.7 \mathrm{~mm}$ were subjected to repeated cycles of heating and quenching until fracture occurred. Heating was performed in an electric furnace (about 20 to 30 min being allowed to reach equilibrium) and quenching in a water bath at about $20^{\circ} \mathrm{C}$. Each specimen was first subjected to 10 thermal cycles with a furnace temperature of $800^{\circ} \mathrm{C}$. If it survived this treatment, 10 cycles were repeated in succession from furnace temperatures at $900,1000,1100$ and $1200^{\circ} \mathrm{C}$, until failure occurred. Surface cracks were observed in a $\times 20$ optical microscope.

\subsection{High temperature strength measurements}

Three-point bend specimens of dimensions $31.8 \mathrm{~mm} \times 2.54 \mathrm{~mm} \times 2.5 \mathrm{~mm} \quad(25.4 \mathrm{~mm} \quad$ span $)$ and $12.7 \mathrm{~mm} \times 2.54 \mathrm{~mm} \times 2.54 \mathrm{~mm}$ (10 mm span) for the turbine and cutting tool ceramics respectively were spark eroded from small commercial rectangular blocks. Testpieces were broken in an Instron testing machine at a cross-head speed of $8.33 \mu \mathrm{m} \mathrm{sec}^{-1}$ and values of the tensile fracture strength $\left(\sigma_{\mathrm{f}}\right)$ were obtained at temperatures ranging from 400 to $1100^{\circ} \mathrm{C}$.

\subsection{Room temperature after shock strength measurements}

Three-point specimens similar to those just desscribed were shocked for 10 cycles at temperatures within the range of 400 to $1200^{\circ} \mathrm{C}$ (at $100^{\circ} \mathrm{C}$ intervals). The shocked specimens were then dried and broken at room temperature in three-point bending, at a cross-head speed of $8.33 \mu \mathrm{m} \mathrm{sec}^{-1}$. Some experiments were also performed to investigate the effects of strain rate and number of repeated shocks on the residual strength of the shocked ceramics.

\subsection{Fracture toughness measurements}

Ceramic testpieces are usually small, so that because of the materials' relatively low resistance to crack propagation, cracking is often fast and catastrophic. Were it possible to control crack propagation in ceramics (which would be feasible in large correctly designed testpieces), incremental values for the work of fracture per unit area of crack growth (i.e. $R$ ) could be measured, and possible variations in $R$ with crack velocity established [16]. Valid toughnesses obtained in this way must be measured when the cracking is stable, otherwise upper-bounds on $R$ are obtained [17]. Thus, taking the stored strain energy at fracture of a ceramic specimen (i.e. the triangular load area under a deflection diagram) that breaks catastrophically is probably an upper bound on some average $R$. The shape of the testpiece is important in questions of crack stability, every specimen having its own "geometric stability factor" (g.s.f.) $[16,18,19]$. Rate dependence in $R$ also affects stability, (i.e. the sign of $\mathrm{d} R / \mathrm{d} \dot{L}$ where $\dot{L}$ is crack velocity), as does the stiffness of the testing machine [18]. It may be shown that even with quite stiff machines, the smallness of most available ceramic specimens causes difficulties in promoting stable cracks, in which case upper-bound "triangular areas" are the best one can hope for [17]. Nevertheless, fracture mechanics formulae for stress intensity factors $(K)$ of given testpiece geometries with starter cracks can be employed to determine toughness, $K_{\mathrm{IC}}^{2}=E R /\left(1-\nu^{2}\right)$, even if the test is catastrophic. We may note in passing that the Griffith formula (strictly appiicable only to small through-cracks in a large plate stressed at its boundaries) is an inherently unstable situation; other crack geometries need not be [18].

Adaptions of commercially available ceramic shapes that should tend to be stable are shown in 


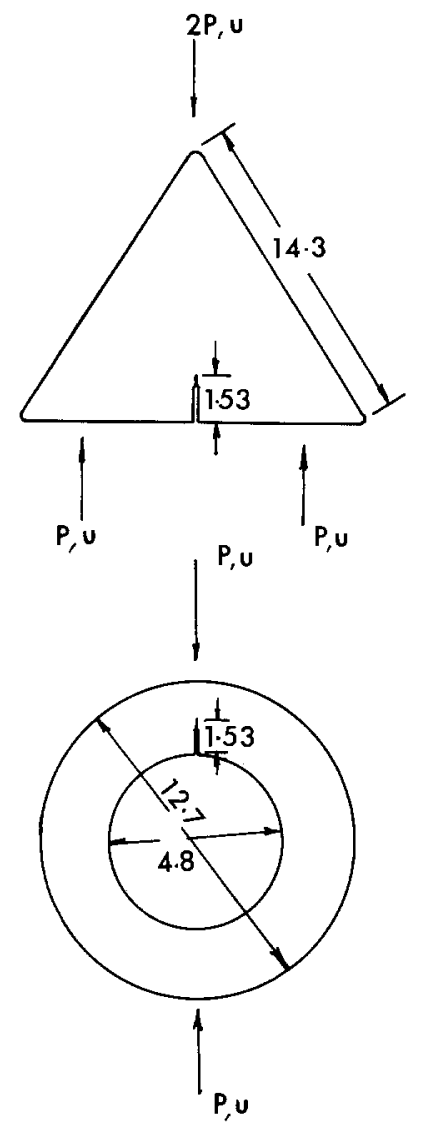

Figure 2 Available tool inserts used as fracture toughness testpieces (all dimensions in $\mathrm{mm}, 4.8 \mathrm{~mm}$ thick).

Fig. 2, where the starter slots were spark machined. When stable cracking occurred, $R$ values were picked up by Gurney's irreversible work area method (Fig. 3a) [16-19]. If unstable cracking occurred, (either because of badly prepared crack fronts, negative $\mathrm{d} R / \mathrm{d} \dot{L}$, or because of the relatively large amount of strain energy stored in the testing machine compared with that in the (small volume) ceramic testpiece), $R$ values could be obtained by using different starter crack lengths and constructing the presumed (unstable) constant $R$ locus (Fig. 3b). Unfortunately, except for the slotted three-point bending test, no stress intensity factors are readily available for the two geometries in Fig. 2. In the case of Kennametal K96, values of $K_{\mathrm{IC}}$ were obtained using the appropriate Gross-Srawley expression for the three-point bend critical stress intensity factor [20]. Much later in our investigation, we discovered that small "part-through" elliptical starter cracks could be successfully introduced into our carbide ceramics using a Vickers hardness indenter, as suggested by Ingelstrom and Nordberg [21] and Kenny [22] . This enabled $u$ s to determine $K_{\mathrm{IC}}$ (and hence initiation $R$ values) for some of our ceramics. Additionally, it was possible to investigate the fracture surfaces of those bend specimens (without starter cracks) that were used for determination of $\sigma_{\mathrm{f}}$ and $\sigma_{\mathrm{a}}$ and establish the size of the flaw from which the final break initiated. Use of "partthrough" crack $K_{\text {IC }}$ formulae for bend bars enabled extra estimates of the toughness at temperature to be gained.

Our toughness determinations thus come from a variety of sources, but all were found to be reasonably self consistent. Note that traditional methods of fracture toughness determination for ceramics are given in references [23-28]

\section{Results and discussion}

\subsection{Traditional thermal shock evaluations}

Table I summarizes the results of the thermal shock tests. The details of shock resistances for the turbine and cutting tool ceramics are given in [17]. From these experiments, it is possible to rate the ceramics according to both their resistance to crack initiation and their resistance to crack
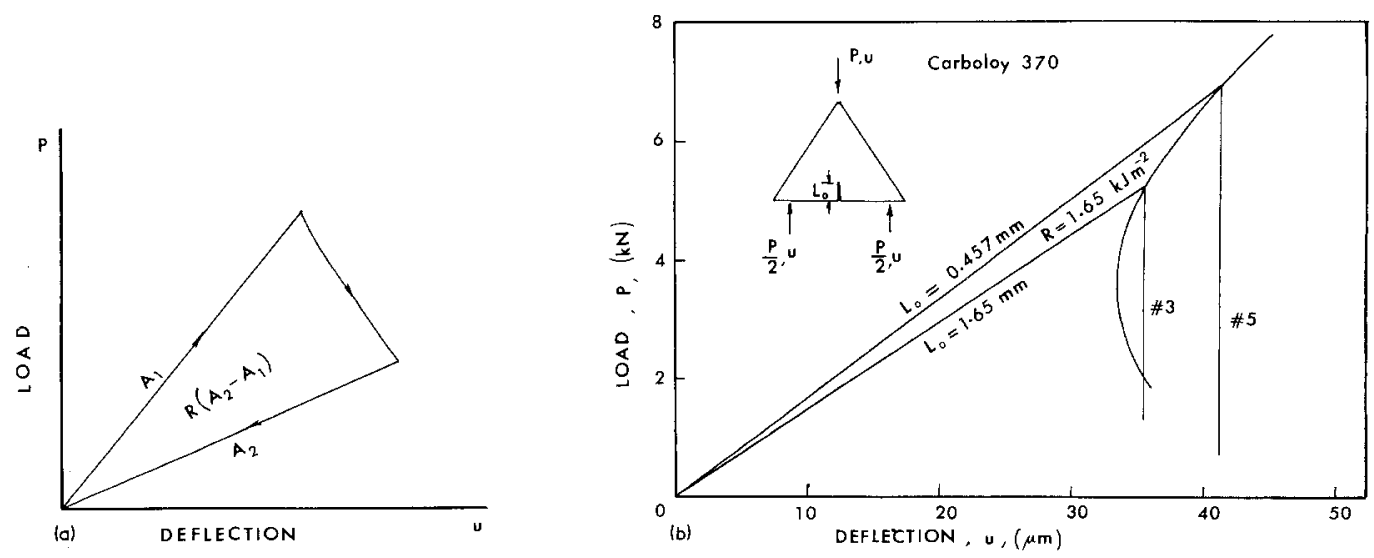

Figure 3 (a) and (b) Fracture toughness determination using Gurney's irreversible work area method. 
TABLE I Evaluation of thermal shock resistances

\begin{tabular}{|c|c|c|c|c|c|c|c|c|c|}
\hline \multirow[t]{2}{*}{ Material } & \multicolumn{4}{|c|}{ Physical properties (R.T.) } & \multicolumn{5}{|c|}{ Thermal cycles completed before failure } \\
\hline & $10^{-60} \mathrm{C}^{-1}$ & $\begin{array}{l}k \\
\left(\mathrm{cal} \mathrm{m} \mathrm{m}^{-1} \sec ^{-10} \mathrm{C}^{-1}\right)\end{array}$ & $\begin{array}{l}E \\
\left(\mathrm{GN} \mathrm{m}^{-2}\right)\end{array}$ & $\begin{array}{l}\sigma_{\mathbf{f}} \\
\left(\mathrm{MN} \mathrm{m}^{-2}\right)\end{array}$ & $800^{\circ} \mathrm{C}$ & $900^{\circ} \mathrm{C}$ & $1000^{\circ} \mathrm{C}$ & $1100^{\circ} \mathrm{C}$ & $1200^{\circ} \mathrm{C}$ \\
\hline M19 & 2.84 & 0.447 & 20.7 & 32 & 10 & 10 & 10 & 10 & $10^{*}$ \\
\hline C140 & -0.27 & 0.65 & 74.5 & 193 & 10 & 10 & 10 & 10 & $10^{*}$ \\
\hline $\mathrm{C} 132$ & -0.27 & 0.65 & 71.9 & 207 & 10 & 10 & 10 & 10 & 1 \\
\hline Carboloy 370 & 6.57 & 11.00 & 560 & 1930 & $10^{\frac{1}{\dagger}}(10)$ & 10 & 4 & & \\
\hline Titan 80 & 7.80 & 5.10 & 428 & 1240 & $10^{\dagger}(3)$ & 7 & & & \\
\hline Titan 60 & 7.80 & 5.10 & 428 & 1450 & $10^{\dagger}(3)$ & 10 & & & \\
\hline Nippon A2 & 7.80 & 4.10 & 310 & 800 & $10^{\dagger}(2)$ & 4 & & & \\
\hline
\end{tabular}

* No failure recorded.

$\dagger$ Number in parentheses indicates cycles for initiation of surface cracks.

TABLE. II Shock quantifying parameters of ceramics

\begin{tabular}{llclr}
\hline Material & $\begin{array}{l}\text { Bend strength } \\
\left.(\mathrm{GN} \mathrm{m})^{-2}\right)\end{array}$ & $\begin{array}{l}k \sigma_{\mathrm{f}} / E \alpha \\
\left(\mathrm{cal} \mathrm{m}^{-1} \mathrm{sec}^{-1}\right) \\
\times 10^{-2}\end{array}$ & $\begin{array}{l}\text { R.T. }\left(K_{\mathrm{IC}} / \alpha_{\mathrm{f}}\right)^{2} \\
(\mathrm{~mm})\end{array}$ & $\begin{array}{l}N_{\mathrm{f}} \\
(\mathrm{cycles})\end{array}$ \\
\hline M19 & 0.032 & 1.29 & 1.628 & $>50$ \\
Nippon A2 & 0.800 & 13.20 & 0.378 & 14 \\
Titan 80 & 1.240 & 19.00 & 0.041 & 17 \\
Titan 60 & 1.450 & 22.20 & 0.097 & 20 \\
C132 & 0.207 & 62.00 & 0.736 & 43 \\
C140 & 0.193 & 56.00 & 0.865 & $>50$ \\
Carboloy 370 & 1.930 & 66.50 & 0.381 & 24 \\
Kennametal K96 & 1.720 & 119.00 & 0.374 & \\
\hline
\end{tabular}

propagation (i.e. extent of damage). For crack initiation caused by thermal shock, the appropriate parameter is $k \sigma_{f} / E \alpha$, listed in the third column of Table II. The larger this number, the lesser chance that flaws will be initiated. For the tool ceramics (which have small Biot moduli) the order of decreasing merit is Carboloy 370, Titan 60, Titan 80 and Nippon A2. These predictions are in agreement with results shown in Table $I$ for data concerning the onset of crack initiation. In the case of turbine ceramics (with rapid heat transfer conditions) M19, C140 and C132 are good thermal shock resistant materials. Although M19 has the smallest $k \sigma_{\mathfrak{f}} / E \alpha$, it yet possesses a high resistance to crack initiation and propagation. In light of its porous structure, these results are not unexpected.

As given in Table II, the crack initiation resistance of the cutting ceramics increases with bend strength $\left(\sigma_{\mathrm{f}}\right)$. For design against crack nucleation, Carboloy 370 would be chosen as the best cutting tool material.

Damage resistance or extent of crack propagation by thermal shocks is characterized by $\left(E R^{*} / \sigma_{\mathrm{f}}^{2}\right)$ or $\left(K_{\mathrm{IC}} / \sigma_{\mathrm{f}}\right)^{2}$, listed in the 4 th column of Table II. The greater this number, the better is its resistance to crack propagation. The number of cycles to complete failure of the ceramics taken from Table $I$ is shown in the 5 th column. It may be seen that in general the greater the magnitude of $\left(K_{\mathrm{IC}} / \sigma_{\mathrm{f}}\right)^{2}$, the greater the value of $N_{\mathrm{f}}$. In order of decreasing merit, these are M19, C140, C132, Carboloy 370, Titan 60, Titan 80 and Nippon A2. Note that Carboloy 370 previously chosen as the best cutting tool ceramic against crack initiation is also a good material on the criterion of crack damage. Conversely, although M19 possesses good damage ressistance to thermal shock its use is highly limited because of its relatively weak strength of $32 \mathrm{MN} \mathrm{m}^{-2}$.

We observe that similar values for $\left(K_{\mathrm{IC}} / \sigma_{\mathrm{f}}\right)^{2}$ can be produced by materials with different absolute values of $K_{\mathrm{IC}}$ and $\sigma_{\mathrm{f}}$ (cf. A2, K96 and 370). The best materials for thermal shock damage resistance are those simultaneously possessing both high toughness and high strength. Such combinations of properties may be achieved with suitable ceramic microstructures. This warrants further investigation on the possible effects of grain size, porosity, reinforced-fibres etc. on tool materials in relation to thermal shock. 


\subsection{Effects of thermal shock and high temperature on the bend strength of ceramics}

Retained room temperature strength versus shocking temperature interval results are shown in Fig. 4a to d respectively, for the Titan 80, Titan 60, Nippon A2 and Carboloy 370 cutting tool ceramics. The first three all follow the Hasselman model, more or less, with a critical quenching temperature interval beyond which there is a marked reduction in residual bend strength. From Table III, the critical quenching temperature differences for Titan 60 and Titan 80 are 427 and $368^{\circ} \mathrm{C}$ respectively. The small values of the effective crack lengths $\left(r_{0}=1.6\right.$ to $\left.1.8 \times 10^{-4} \mathrm{~m}\right)$ as estimated from Equation 1 for both carbides explains the catastrophic spreading and arrest behaviour at $\Delta T_{c}$. The experimental values of critical quenching temperature difference obtained for Titan 80 and Titan 60 as inferred in Fig. $4 \mathrm{a}$ and $\mathrm{b}$ are in very good agreement with theory. Also, the predictions of retained strength given by the Hasselman model (Equation 5) agree quite well with the experiments (Table IV). The results show that Titan 60 is better than Titan 80 as far as $\Delta T_{\mathrm{c}}$ is concerned. For Nippon A2, some
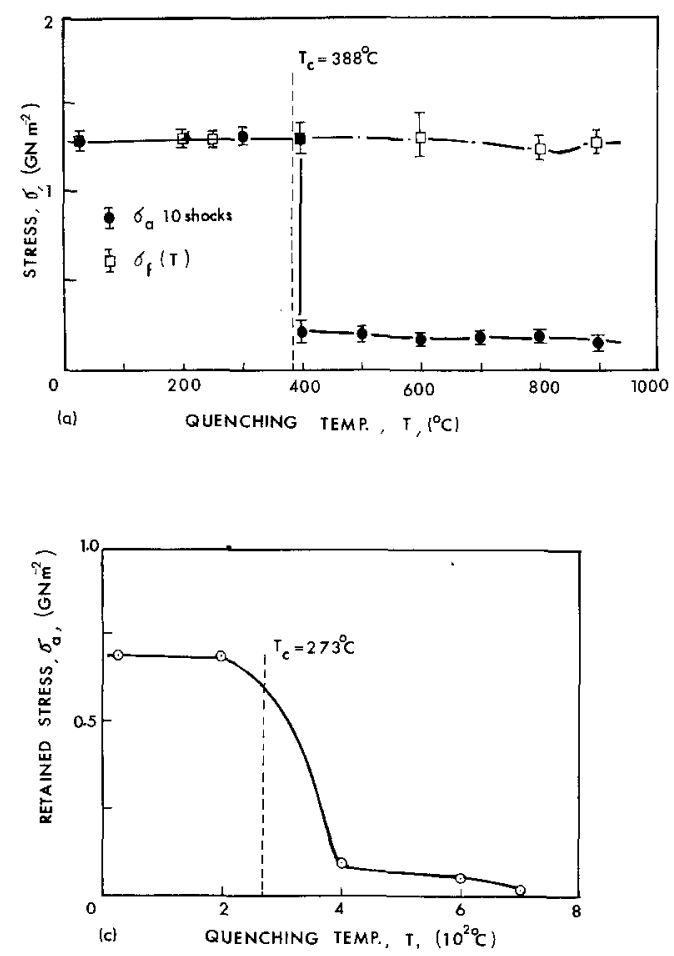

TABLE III Estimation of critical quenching temperature difference $\left(\Delta T_{\mathrm{c}}\right)$ and effective crack length $\left(r_{0}\right)$

\begin{tabular}{llrr}
\hline Material & $\begin{array}{l}\text { Biot modulus } \\
(B=a h / k)\end{array}$ & $\begin{array}{r}\Delta T_{\mathbf{c}} \\
\left({ }^{\circ} \mathrm{C}\right)\end{array}$ & \multicolumn{1}{c}{$\begin{array}{l}r_{0} \\
\left(10^{4} \mathrm{~m}\right)\end{array}$} \\
\hline M19 & 28.40 & 217 & 13.00 \\
C132 & 19.50 & 7150 & 6.17 \\
C140 & 19.50 & 6450 & 7.25 \\
370 & 1.15 & 1280 & 1.30 \\
A2 & 3.10 & 253 & 3.96 \\
Ti60 & 2.50 & 427 & 1.81 \\
\hline
\end{tabular}

Note: For $B>5.0, \Delta T_{\mathrm{c}} \approx \sigma_{\mathrm{f}}(1-v) /(E \alpha)$; for $B<5.0$, $\Delta T_{\mathbf{c}} \approx[3.25(1-\nu) /(a h)]\left(k \sigma_{\mathrm{f}} / E \alpha\right)$.

of the testpieces broke during shocking, when the shock temperatures were above $500^{\circ} \mathrm{C}$. At a quenching temperature difference of $380^{\circ} \mathrm{C}$ (i.e. $400-20^{\circ} \mathrm{C}$ ), the strength retained after ten thermal cycles was about $15 \%$ of the unshocked specimen tested at room temperature, which was close to that predicted by the Hasselman model. Unfortunately, our data on Nippon A2 is limited but the theoretical critical quenching temperature difference of $253^{\circ} \mathrm{C}$ (i.e. shock temperature of $273^{\circ} \mathrm{C}$ ) is not unreasonable. The unshocked high temperature strength of Titan 80 remains relatively constant to temperatures beyond the critical temperature (Fig. 4a).
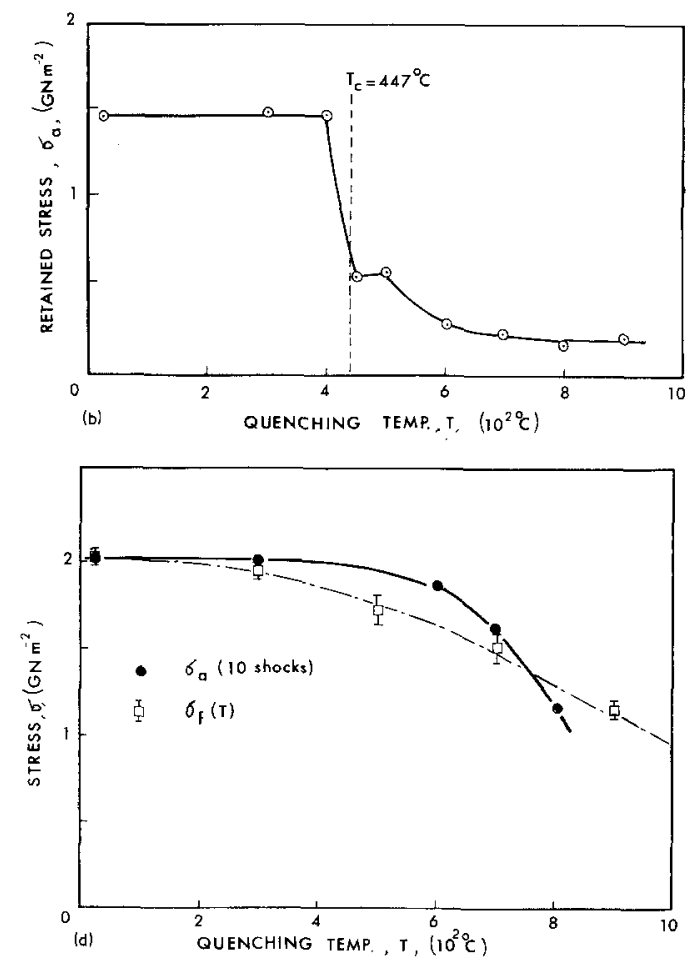

Figure 4 (a) Thermal shock and high temperature strength for Titan 80. (b) Thermal shock strength for Titan 60 . (c) Thermal shock strength for Nippon A2. (d) Thermal shock and high temperature strength for the higher density Carboloy 370. 
T ABLE IV Predictions of strength retained after thermal shock

\begin{tabular}{|c|c|c|c|c|}
\hline \multirow[t]{2}{*}{ Material } & \multirow{2}{*}{$\begin{array}{l}\sigma_{\mathrm{f}}\left(\mathrm{GN} \mathrm{m}^{-2}\right) \\
\text { (R.T.) }\end{array}$} & \multicolumn{2}{|l|}{$\sigma_{\mathrm{a}} / \sigma_{\mathrm{f}}$} & \multirow{2}{*}{ 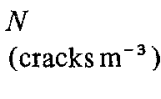 } \\
\hline & & Observed & Calculated & \\
\hline Nippon A2 & 0.800 & 0.140 & 0.194 & $6 \times 10^{8}$ \\
\hline Titan 80 & 1.240 & 0.139 & 0.100 & $6 \times 10^{9}$ \\
\hline Titan 60 & 1.450 & 0.143 & 0.120 & $2.4 \times 10^{9}$ \\
\hline Carboloy 370 & 1.930 & 0.605 & & \\
\hline
\end{tabular}

The behaviour of the higher density Carboloy 370 in Fig. 4d, as reported in [11], is very interesting. The theoretical $\Delta T_{\mathrm{c}}$ is some $1280^{\circ} \mathrm{C}$ and the effective crack length is $r_{0} \approx 4 \times 10^{-2} \mathrm{~cm}$, which for $N<1000$ occurs to the left of the stability minima in [3], thus suggesting an instantaneous retained strength degradation only upon shocking from temperatures greater than $1300^{\circ} \mathrm{C}$. However, there is a gradual reduction in residual strength for temperatures much lower than $1300^{\circ} \mathrm{C}$, and in general terms it is not possible to distinguish between the bend strengths measured at high temperatures and those measured at room temperature after having been shocked from similar high temperatures. Above $800^{\circ} \mathrm{C}, 370$ is oxidized and thermally expanded on all sides, which could very well explain the gradual strength loss above $800^{\circ} \mathrm{C}$. The lower density Carboloy 370 had much lower retained strengths, particularly after repeated shocking. The results are illustrated in Fig. 10, and discussed later in Section 3.5 .

Gradual after-shock strength loss behaviour (similar to the higher density Carboloy 370), which is at variance with the Hasselman model, is shown by the turbine ceramics, Fig. 5a to c. While M19 and C140 do not show any strength degradation when tested at high temperatures (700 to $\left.1100^{\circ} \mathrm{C}\right)$ in the as-received unshocked condition, C132 does exhibit significant strength loss as the temperature increases. A plausible reason is the occurrence of subcritical crack growth and plastic flow at such flaws. This assumption is substantiated by evidence shown in some load-deflection diagrams which display obvious non-linearities before final fracture. The strength retained by the shocked specimens (i.e. after ten thermal cycles at a given quenching temperature difference) decreases gradually with increasing shock temperature for all three ceramics. Of the two cordierites,
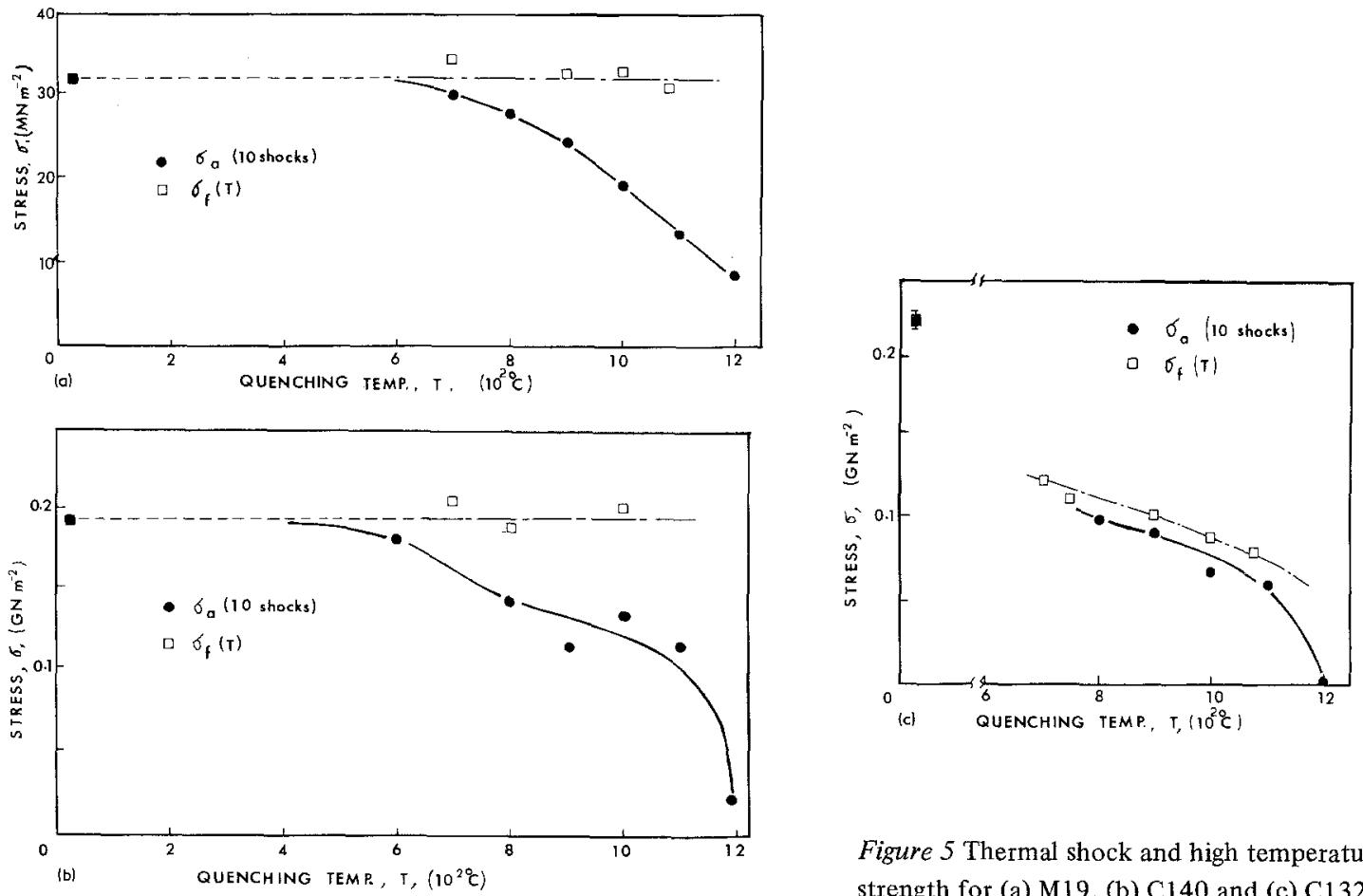

Figure 5 Thermal shock and high temperature strength for (a) M19, (b) C140 and (c) C132. 
the results show that $\mathrm{C} 140$ should be superior at high temperatures.

In summary, the variation of retained strength after thermal shock is divided into two characteristic behaviours: (1) materials possessing a gradual strength degradation as the quenching temperature difference increases; (e.g. Carboloy 370, C140, M19); (2) materials with instantaneous strength

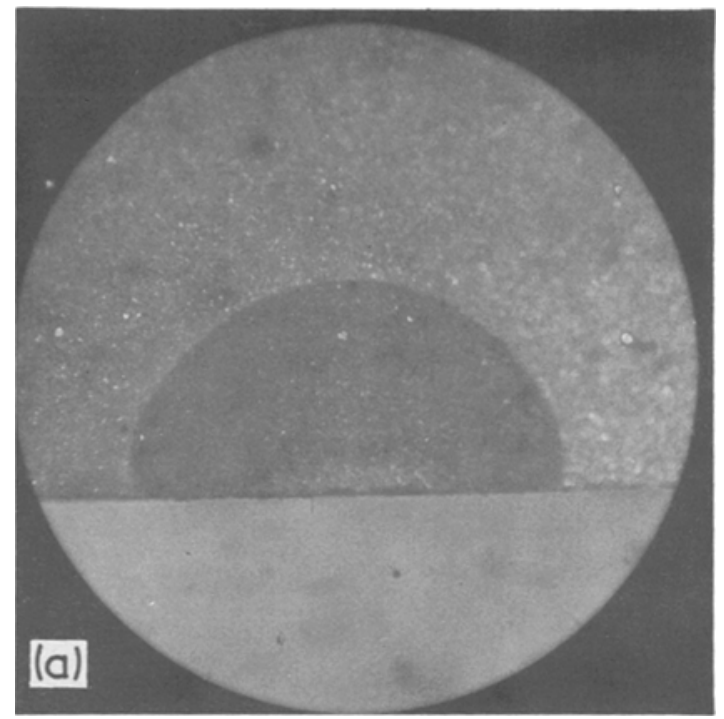

drop at critical quenching temperature difference (e.g. Nippon A2, Titan 60 and Titan 80).

\subsection{Fracture toughness results}

As explained in Section 2.5, our toughness data were obtained by various techniques. A summary of the results is given in Table V. Some additional results on rate effects in $K_{\mathrm{IC}}$ are given in Section 3.6 later. The toughest tool carbides are Carboloy 370 and Kennametal K96, followed by Nipon A2, Titan 60, with Titan 80 the most brittle. The turbine ceramics all have low toughness, the best (C140) corresponding with the toughness of Titan 80.

Fig. 6a shows the elliptical starter crack produced by a Vickers indentation in Titan 80 . The subsequent fracture surface resulted from breaking in three-point bending at $600^{\circ} \mathrm{C}$. Fig. $6 \mathrm{~b}$ and $\mathrm{c}$ show the flaws from which final structure in unnotched three-point bending took place at room temperature in Nippon $\mathrm{A} 2$ and $700^{\circ} \mathrm{C}$ in

Figure 6 Typical initial flaw geometries for (a) Titan 80 ( $\times 36$ ); (b) Nippon A2 $(\times 30)$ and (c) Carboloy $370(\times 30)$.
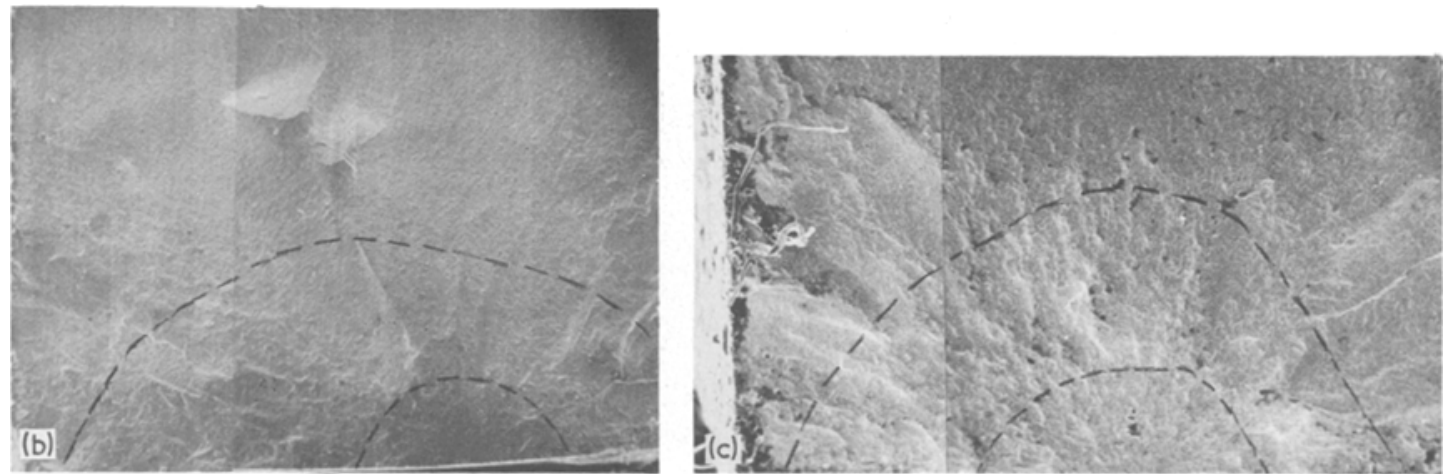

Notes to Table $V$

(a) Three-point bend notched by spark erosion $K_{\text {IC }}$ formula in [20]. $R$ derived from $\left(1-\nu^{2}\right)\left(K_{\text {IC }}^{2} / E\right)$.

(b) Precracked by hardness indentation technique $K_{\mathrm{IC}}$ formulae in e.g. [21].R derived from $\left(1-\nu^{2}\right)$ $\left(K_{\mathrm{IC}}^{2} / E\right)$.

(c) Three point bend unnotched high temperature test. Final flaw size determined after test. $K_{\mathrm{IC}}$ formulae in $[20,21] . R$ derived from $\left(1-\nu^{2}\right)\left(K_{\mathrm{IC}}^{2} / E\right)$.

(d) Diametrical compression of cracked ring $[16,28]$, to determine $R . K_{\mathrm{IC}}$ derived from $\sqrt{ }\left[E R /\left(1-\nu^{2}\right)\right]$.

(e) Bending of precracked triangular testpiece [17] to determine $R . K_{\mathrm{IC}}$ derived from $\sqrt{ }\left[E R /\left(1-v^{2}\right)\right]$.

(f) After-shock three-point-bend test. Final flaw size determined after test. $K_{\mathrm{IC}}$ formulae in [20,21].R derived from $\left(1-\nu^{2}\right)\left(K_{\mathrm{IC}}^{2} / E\right)$.

$E$ values for conversions between $R$ and $K_{\mathrm{IC}}$ are given in Table I. Except for C140, the room temperature

$E$ were applicable at higher temperatures. For C140 see Section 3.5 .

* Number in brackets after temperature is the number of repeated shocks.

$\dagger$ Toughness testing performed in the presence of liquid water. 
TABLE V Fracture toughness values for various ceramics

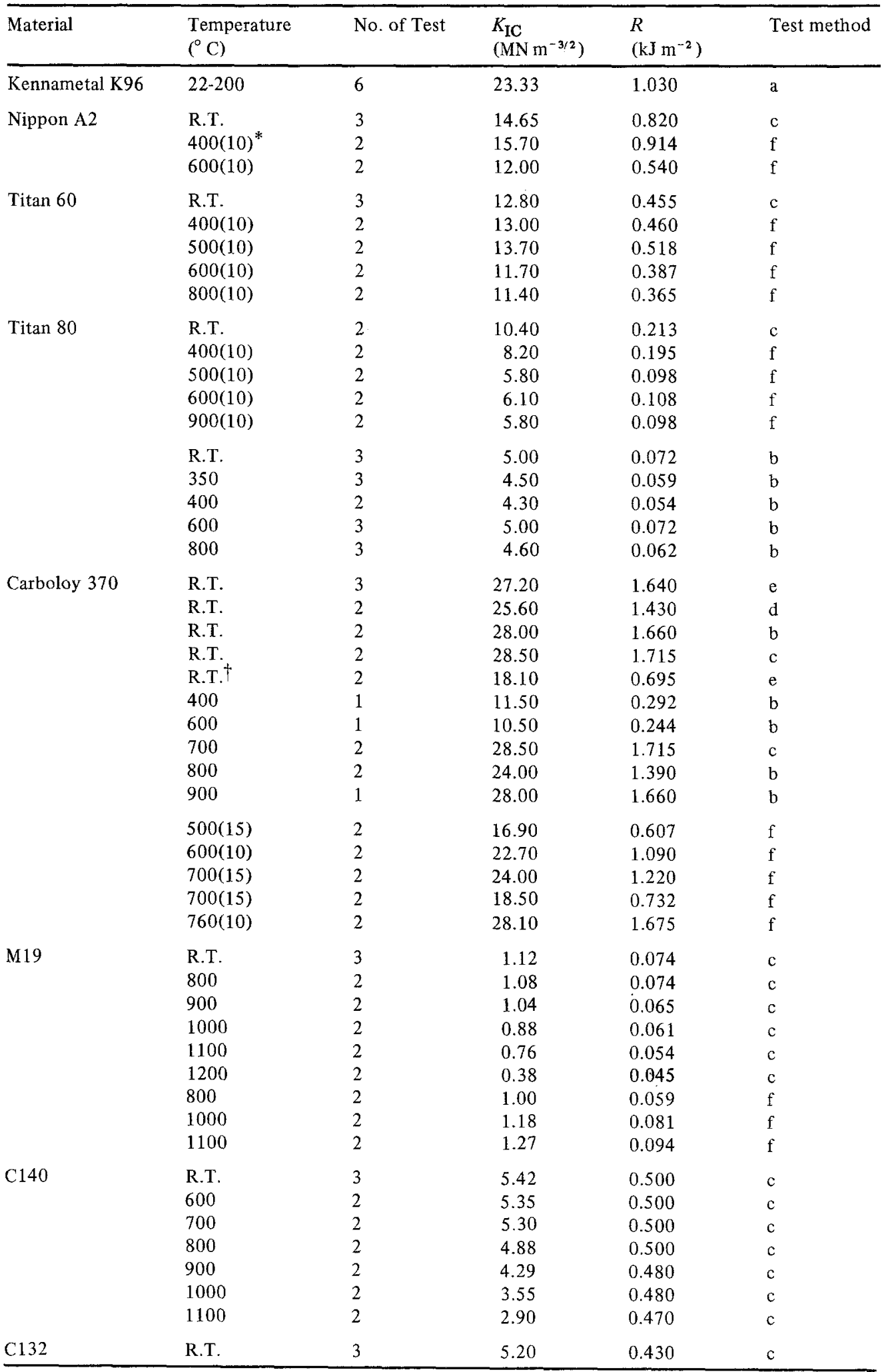



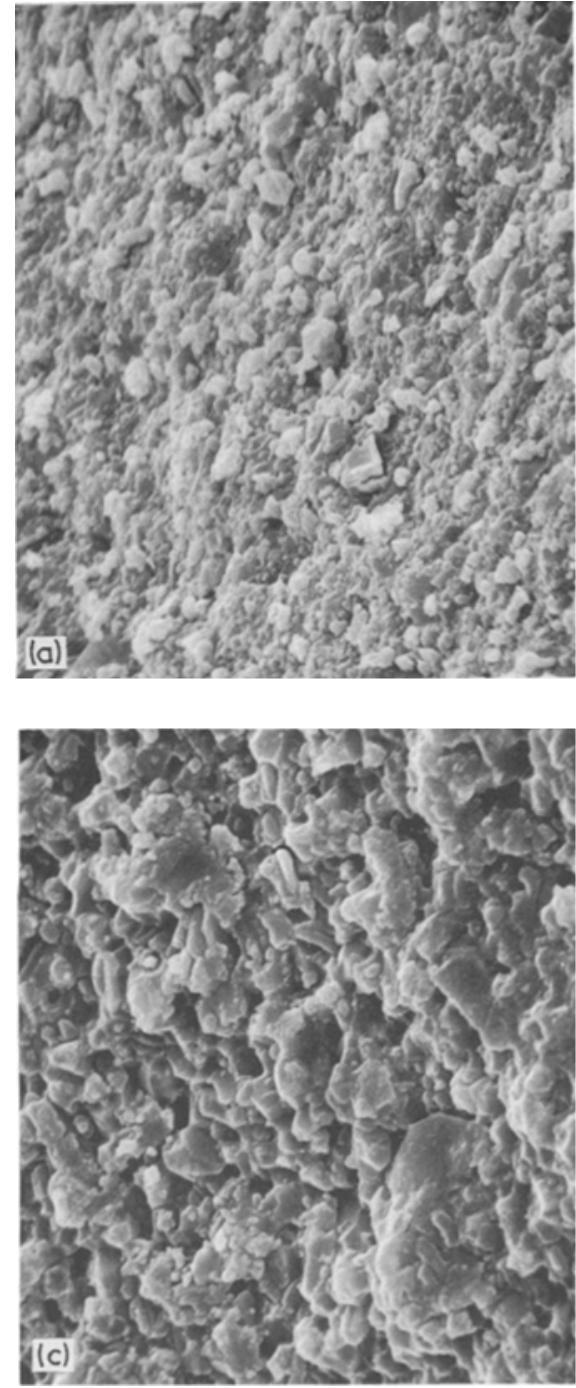
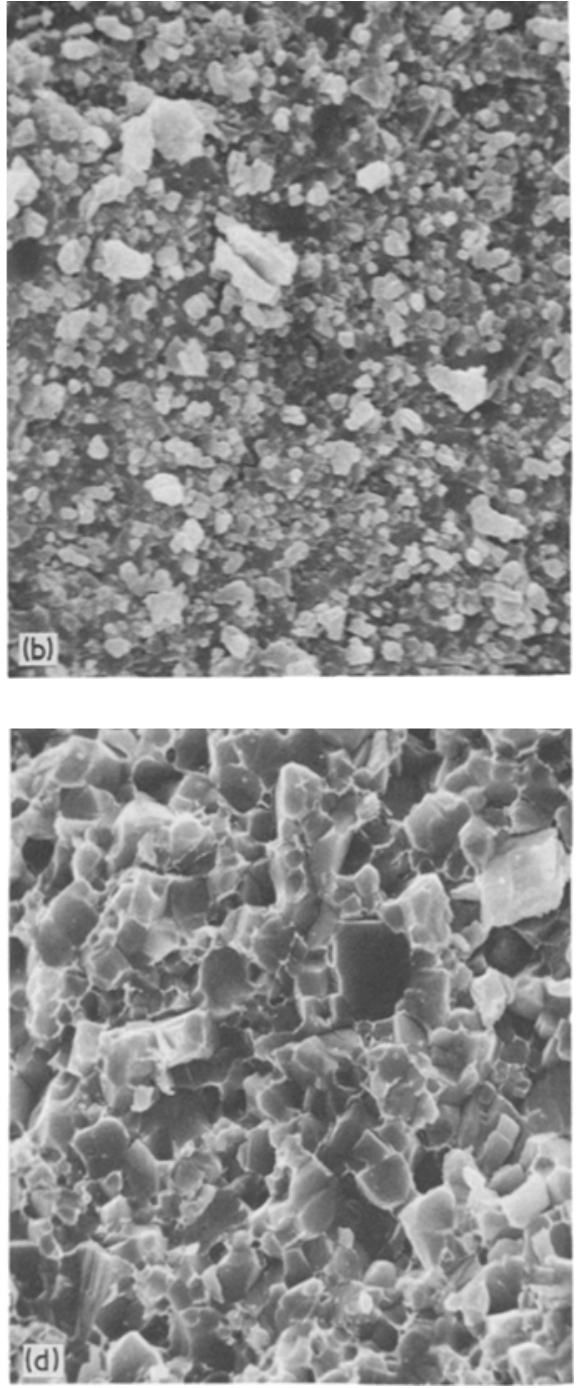

Figure 7 Typical fracture surfaces for (a) Nippon A2, within $r_{f}(\times 1300)$; (b) Nippon A2, outside $r_{f}$ and fractured mechanically (X 1300); (c) Titan 80, within $r_{f}(\times 2600)$ and (d) Titan 80, outside $r_{f}$, fractured mechanically $(X 2600)$.

Carboloy 370 respectively.

Scanning electron micrographs of typical fracture surfaces are shown in Fig. 7a to d. Fig. 7a and $b$ relate to Nippon $A 2$, the other pair to Titan 80. Fracture surfaces from within the shocked initiation regions (i.e. within $r_{\mathrm{f}}$ ) are shown in Fig. $7 \mathrm{a}$ and $c$. The subsequent fracture surfaces produced mechanically by three-point bending at room temperature in the shocked samples (i.e. in the region outside $r_{f}$ ) appeared the same as those fracture surfaces throughout the cross-section of unshocked samples broken in three-point bending at room temperature. Typical examples are shown in Fig. $7 b$ and $d$. The fracture surfaces produced by quenching through $\Delta T_{c}$ are more "powdery" in appearance than the room temperature surfaces.

Table $\mathrm{V}$ shows that the room temperature fracture toughnesses of unshocked and shocked samples are essentially the same (within our experimental error). This suggests that the reduction in room temperature retained strength after shock is caused principally by enlarged $r_{\mathbf{f}}$. Plots of a "corrected $\sigma_{\mathrm{a}}$ " versus $1 / \sqrt{ } r_{\mathrm{f}}$ should be straight lines through the origin of slope $K_{\mathbf{I C}}^{\dagger}$.

${ }^{\dagger} K_{\mathrm{IC}}=\sigma_{\mathrm{a}} \sqrt{ } r_{\mathbf{f}} Y$, where $Y$ is different for elliptical and straight starter crack geometries. Thus, Fig. 8 plots $\left(\sigma_{\mathbf{a}} Y\right)$ versus $1 / \sqrt{ } r_{\mathrm{f}}$, where $\left(\sigma_{\mathrm{a}} Y\right)$ is the "corrected $\sigma_{\mathrm{a}}$ ". 


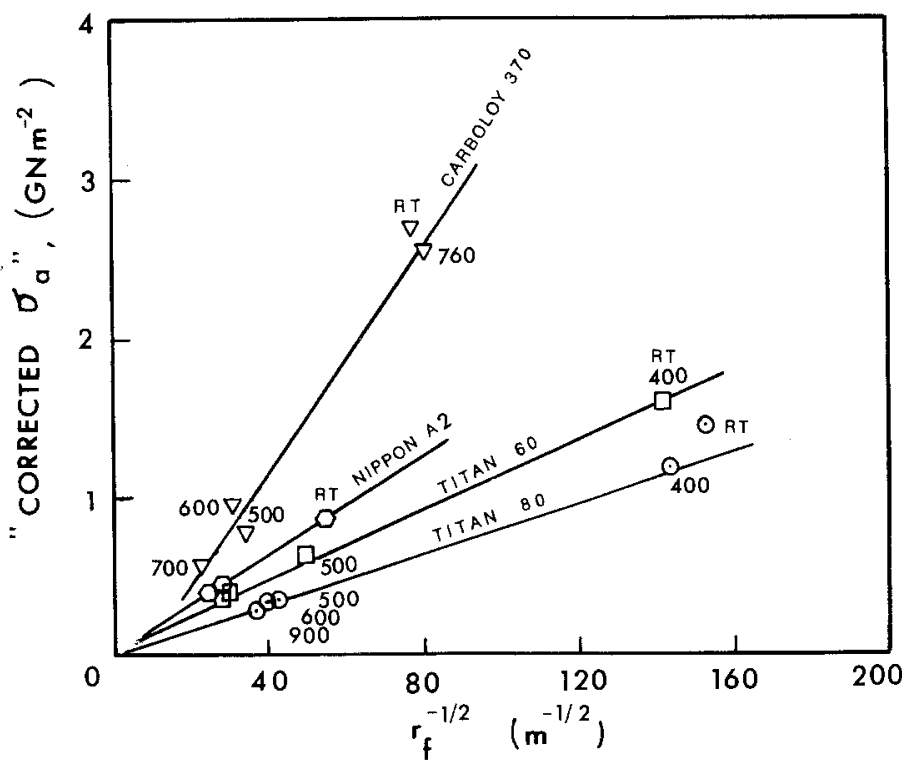

Figure 8 Plots of "corrected $\sigma_{\mathrm{a}}$ " versus $\left(r_{\mathrm{f}}\right)^{-1 / 2}$ for the tool ceramics.
Fig. 8 shows the experimental results. Those materials following the Hasselman model (particularly Titan 80) "should" have a set of identical points for one flaw size at $\sigma_{\mathfrak{f}}$ (if they have not been shocked through $\Delta T_{\mathrm{c}}$ ) and another set of identical points for one $r_{\mathrm{f}}$ after shocking through $\Delta T_{\mathrm{c}}$. Shocks much more severe than $\Delta T_{\mathrm{c}}$ should give extra points with small $1 / \sqrt{ } r_{\mathrm{f}}$.

It is worth mentioning that there is evidence that water retained in the samples after shocking can significantly reduce $K_{\text {IC }}$, sometimes by a factor of two in the case of Carboloy 370 (Table $\mathrm{V})$. Some of the scatter in the room temperature $K_{\text {IC }}$ (e.g. Carboloy 370 ) may be caused by such an effect, and it may be present in Fig. 8.

\subsection{Correlation of strength loss and damage resistance parameter}

Recently, Ainsworth and Herron have shown [2] that a modified damage resistance parameter
$\left(E R / \sigma_{\mathbf{f}}^{2} V\right)$, calculated from room temperature property values, can be used to evaluate the loss in strength of selected refractories subjected to thermal cycling in the "brittle" temperature range (i.e. $>\Delta T_{\mathrm{c}}$ ). Note that $V$ is the volume of the material under stress; incorporation of $V$ in the parameter reveals a size effect on thermal-shockinduced damage. Similar plots have been attempted for the ceramics studied here. Percentage strength losses after various thermal shocks are shown in Table VI, for all materials tested (i.e. those for which Hasselman's model is obeyed and also those not obeying the model). In general, there is no correlation when strength loss is plotted against the damage resistance parameter $\left(K_{\mathrm{IC}} / \sigma_{\mathrm{f}}\right)^{2}$ using room temperature values. This perhaps is not unexpected since the critical temperature differences required for crack initiation in the different ceramics vary considerably, whereas the refractories studied by Ainsworth and Herron

TABLE VI Correlation of strength loss and damage resistance parameter

\begin{tabular}{|c|c|c|c|c|c|c|}
\hline \multirow[t]{2}{*}{ Material } & \multirow{2}{*}{$\begin{array}{l}\left(K_{\mathrm{IC}} / \sigma_{\mathrm{f}}\right)^{2}(\mathrm{~mm}) \\
\text { (R.T. values) }\end{array}$} & \multicolumn{5}{|c|}{$\%$ strength loss } \\
\hline & & $800^{\circ} \mathrm{C}$ & $900^{\circ} \mathrm{C}$ & $1000^{\circ} \mathrm{C}$ & $1100^{\circ} \mathrm{C}$ & $1200^{\circ} \mathrm{C}$ \\
\hline Titan 80 & 0.041 & 89.3 & 89 & 89 & 90 & 90 \\
\hline Titan 60 & 0.097 & 75.4 & 88 & 88 & 89 & 90 \\
\hline Nippon A2 & 0.378 & 97.5 & 98 & 98 & 98 & 98 \\
\hline Carboloy 370 & 0.381 & 39.5 & 70 & 96 & 97 & 97 \\
\hline M19 & 1.628 & 14.3 & 24.4 & 40.7 & 58.4 & 73.50 \\
\hline $\mathrm{C} 140$ & 0.865 & 17.9 & 27.6 & 45.9 & 64.3 & 80.8 \\
\hline $\mathrm{C} 132$ & 0.736 & 52.2 & 56.3 & 70 & 78.0 & 98.00 \\
\hline
\end{tabular}

Note: $1 . K_{\mathrm{IC}}$ and $\sigma_{\mathrm{f}}$ are based on R.T. measurements.

2. $\%$ strength loss $=\left(\sigma_{\mathrm{f}}-\sigma_{\mathrm{a}}\right) / \sigma_{\mathrm{f}} \times 100 \%$ where $\sigma_{\mathrm{f}}=$ break strength at R.T. and $\sigma_{\mathrm{a}}=$ strength retained after thermal shock for ten temperature cycles. 
have similar $\Delta T_{\mathrm{c}}$ along with instantaneous strength loss.

Despite this, some useful information can still be derived from Table VI. It may be seen that for Titan 60, Titan 80, and Nippon A2 (for all of which Hasselman's model applies) the strength loss is insensitive to the shock severity above their respective $\Delta T_{\mathrm{c}}$, whereas the strength loss of the other ceramics is highly dependent on the shock temperature, i.e. the greater the shock the more the strength loss. There are many possible reasons for this observation, amongst which the most likely is that at elevated temperatures, the magnitude of the shock damage resistance parameter is gradually diminished because of temperature variations in $\sigma_{\mathrm{f}}$ and $K_{\mathrm{IC}}=\sqrt{ }\left[E R /\left(1-\nu^{2}\right)\right]$. Then, instead of one $\left(K_{\mathrm{IC}} / \sigma_{\mathrm{f}}\right)^{2}$ value for a given material (based on room temperature values), different $\left(K_{\mathrm{IC}} / \sigma_{\mathrm{f}}\right)^{2}$ are appropriate to different temperatures. When the percentage strength loss resulting from shocking at a given temperature is plotted

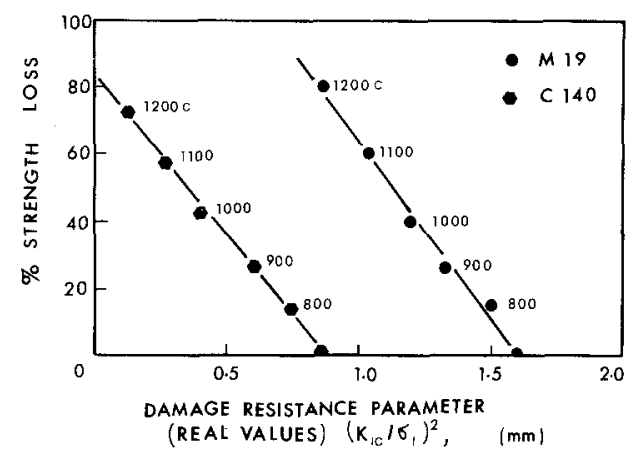

Figure 9 Correlation between thermal shock strength loss and $\left(K_{\mathrm{IC}} / \sigma_{\mathfrak{f}}\right)^{2}$ at current high temperatures.

against the relevant $\left(K_{\mathrm{IC}} / \sigma_{\mathrm{f}}\right)^{2}$, distinct correlations are possible. To illustrate this point, the data for M19 and C140 are plotted in Fig. 9, where we see good correlation between $\left(1-\sigma_{\mathrm{a}} / \sigma_{\mathrm{f}}\right)$ and the $\left(K_{\mathrm{IC}} / \sigma_{\mathrm{f}}\right)^{2}$ varying with temperature. For both M19 and $\mathrm{C} 140, K_{\mathrm{IC}}$ was not measured directly, because it was impossible to make starter cracks with hardness indenters (the specimens split), and also because we could not reliably identify after breaking the very small flaws from which the final fractures occurred. Thus, $E$ and $R$ were separately measured as described in Section 3.3. In the case of M19, where cracking was relatively stable, confidence can be placed in the toughness values (which decreased with temperature) whereas, with C140, unstable cracking probably causes upperbound estimates for $R$ (which were more or less independent of temperature). In addition, there is confusion as to whether $E$ varies with temperature for $\mathrm{C} 140$; our results indicate that $E$ remains constant at $74.5 \mathrm{GN} \mathrm{m}^{-2}$ between room temperature and $500^{\circ} \mathrm{C}$, and then decreases linearly to $21 \mathrm{GN} \mathrm{m}^{-2}$ at $1000^{\circ} \mathrm{C}$, whereas work elsewhere on the same material did not find the reduction in $E$. As shown in Fig. $5 \mathrm{~b}$ the unshocked $\sigma_{\mathrm{f}}$ for $\mathrm{C} 140$ does not vary with temperature. Variations in $\left(K_{\mathrm{IC}} / \sigma_{\mathrm{f}}\right)^{2}$ in Fig. 9 for C140, therefore, come from variations in $E$ and, given that the $R$ values is an upperbound, the relationship between the parameters is satisfactory. We may note that even if $E$ is really independent of temperature, (giving only one value for $\left.\left(K_{\mathrm{IC}} / \sigma_{\mathrm{f}}\right)^{2}\right)$ the percentage strength losses in $\mathrm{C} 140$ after shock, could still be explained in terms of progressively enlarged $r_{\mathbf{f}}$ after shocking. Materials which follow the Hasselman model also have a single $\left(K_{\text {IC }} / \sigma_{f}\right)^{2}$ value, for region $\mathrm{C}$ in Fig. 1. They also have only one $\left(1-\sigma_{\mathrm{a}} / \sigma_{\mathrm{f}}\right)$ value for shocking through $\Delta T_{\mathbf{c}}$ because no sub-critical growth occurs for less severe shocks. On the other hand $\mathrm{C} 140$, even though it may have only a single $\left(K_{\mathrm{IC}} / \sigma_{\mathrm{f}}\right)^{2}$ value, has a varying $\left(1-\sigma_{\mathbf{a}} / \sigma_{f}\right)$ because of sub-critical crack growth.

\subsection{Effect of number of repeated shocks}

In general terms, repeated shock cumulatively damage a solid by encouraging increments of "subcritical" crack growth at every quench. Thus, $\sigma_{\mathrm{a}}$ decrease as the number of shocks increase, particularly for materials which do not obey the Hasselman model. That slow crack growth is the cause of smaller $\sigma_{\mathrm{a}}$ may be confirmed by the fact

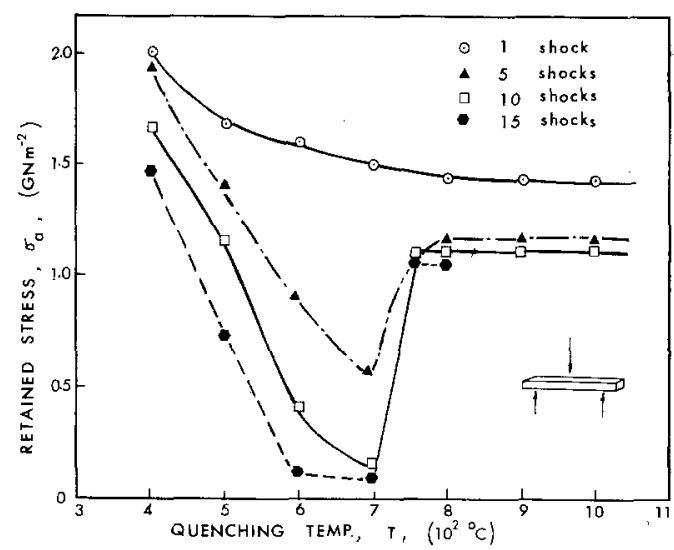

Figure 10 Variation of after shock retained strength $\left(\sigma_{\mathbf{a}}\right)$ with quenching temperature $(T)$ for the lower density Carboloy 370 subjected to repeated shocks. 


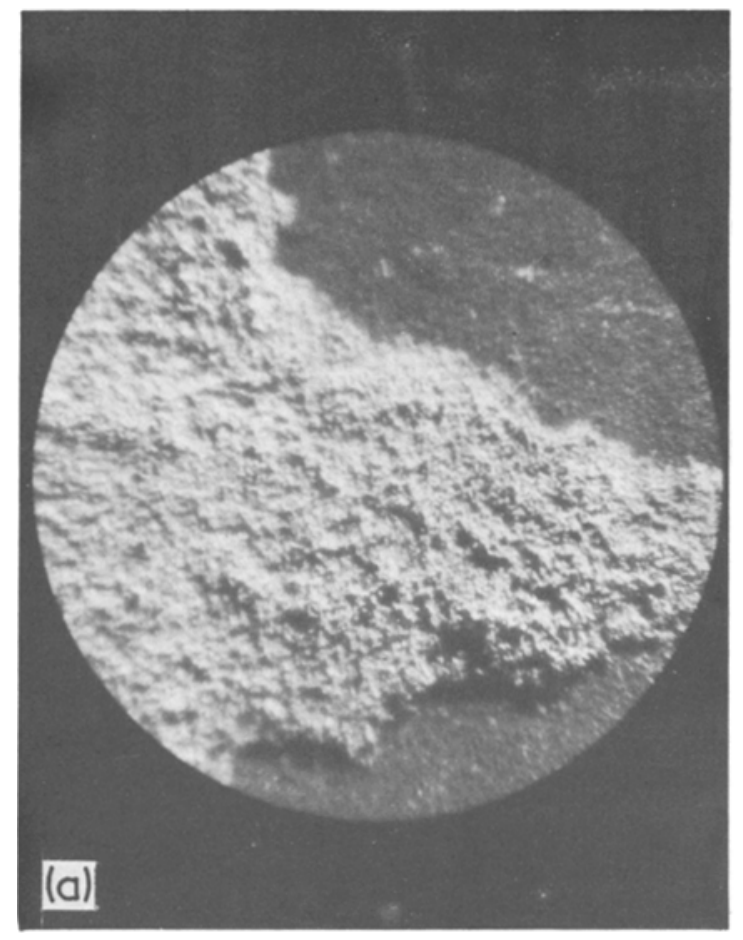

that the room temperature toughness of shocked samples is essentially the same as the toughness of unshocked specimens.

The behaviour of the lower density Carboloy 370 is particularly interesting. For quenching temperature differences up to about $700^{\circ} \mathrm{C}$, greater numbers of repeated shocks progressively reduce the retained strength (Fig. 10). Above some $750^{\circ} \mathrm{C}$, the material oxidizes very rapidly, however, and the retained strength rises again to very high levels. Notice that the single shock data do not display this behaviour. Evidently the oxidized specimens quenched many times with separate differences of at least $750^{\circ} \mathrm{C}$ are better able to withstand the transient shocks than the unoxidized testpieces quenched with smaller temperature differences. Fig. 11 a to $c$ show appearances of the oxidized and unoxidized specimens. Below $700^{\circ} \mathrm{C}, \sigma_{\mathrm{a}}$ is reduced because of sub-critical flaw growth (cracks can be readily seen after shocking and non-linearities were observed in the load-deflection plots of the bend specimens used to determine $\sigma_{\mathrm{a}}$ ). The density of the propagated cracks increases with the number of repeated shocks. However, after oxidation, the toughness becomes greater, so that the damage resistance parameter $\left(K_{\mathrm{IC}} / \sigma_{\mathrm{f}}\right)$ increases. Thus, it is more difficult for large cracks to appear in the system, and the "undeveloped" small flaws are reflected in re-
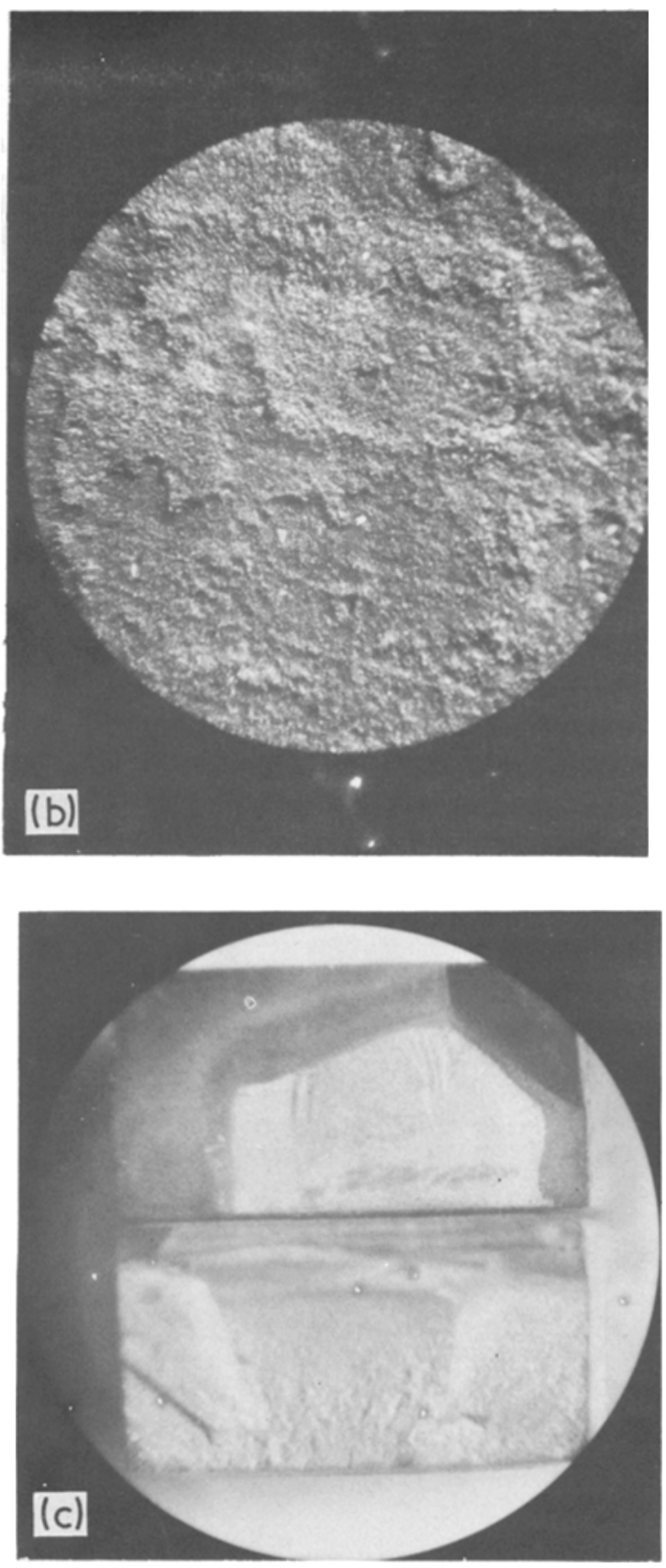

Figure 11 Typical appearances of (a) oxidized and (b) unoxidized Carboloy 370. (c) Top: fracture cross-section of unoxidized testpiece (note thermal shock induced cracks). Bottom: fracture cross-section of oxidized testpiece. (a) and (b) $\times 36$, (c) $\times 10$.

stored $\sigma_{\mathrm{a}}$. For example, the $\sigma_{\mathrm{a}}$ value $(\sim 235 \mathrm{MN}$ $\mathrm{m}^{-2}$ ) after 10 shocks from $700^{\circ} \mathrm{C}$ is commensurate with a flaw size of about $1.5 \mathrm{~mm}$; the corresponding flaw size for $\sigma_{\mathrm{a}}=1.36 \mathrm{GN} \mathrm{m}^{-2}$ after 10 shocks from $760^{\circ} \mathrm{C}$ is about $0.15 \mathrm{~mm}$.

On the other hand, experiments have shown 
that for materials which obey Hasselman's model such as Titan 80 , repeated shocks (e.g. 1 shock and 10 shocks) have negligible effects on the room temperature retained strength $\left(\sigma_{\mathbf{a}}\right)$. Such results should be expected and follow from Fig. 1.

\subsection{Effect of strain rate on results}

The strength data (for both unshocked and shocked samples) presented thus far were all obtained at a testing machine crosshead velocity of $8 \mu \mathrm{m} \mathrm{sec}^{-1}$. Additional data for room temperature unshocked strength $\left(\sigma_{\mathfrak{f}}\right)$ and retained after-shock strength $\left(\sigma_{\mathrm{a}}\right)$ were obtained as cross-head velocities

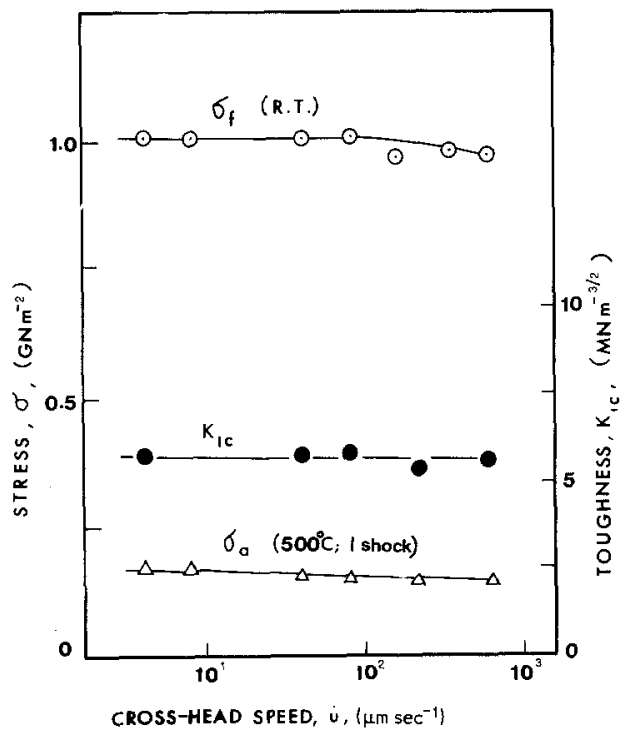

Figure 12 Variation of $K_{\mathrm{IC}}, \sigma_{\mathrm{f}}$ and $\sigma_{\mathrm{a}}\left[1\right.$ shock at $\left.500^{\circ} \mathrm{C}\right]$ with cross-head speed $(\dot{u})$ for Titan 80 .

up to $667 \mu \mathrm{m} \mathrm{sec}^{-1}$, as illustrated in Fig. 12 for Titan 80. Also plotted on Fig. 12 are $K_{\text {IC }}$ data over the same range of crosshead velocities, determined from the $\sigma_{f}$ loads and "after-the-fact" fractographic identification of the size of the "kernal" flaw from which final fracture took place; use of an appropriate fracture mechanics formula with the fracture load and flaw shape and size gives $K_{\mathrm{IC}}$ [21]. Both $\sigma_{\mathbf{f}}$ and $\sigma_{\mathbf{a}}$ remain comparatively constant for the complete range of cross-head speeds investigated; $K_{\text {IC }}$ does the same.

Fig. 13 shows the rate effects on $\sigma_{a}$ for Carboloy 370 , where now the number of shocks and the temperature from which shocking took place are important. The $600^{\circ} \mathrm{C}$ data are lower than the $500^{\circ} \mathrm{C}$, but the $1000^{\circ} \mathrm{C}$ results return to higher values similar to the $500^{\circ} \mathrm{C}$ data because of

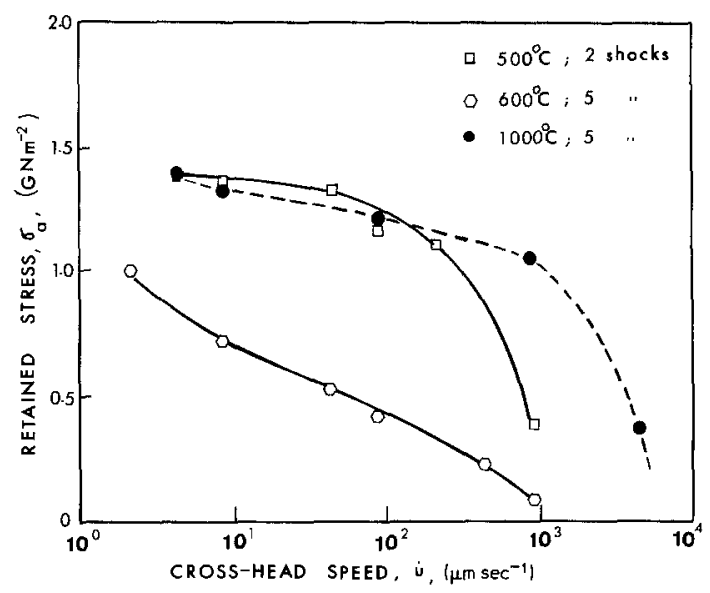

Figure 13 Effects of $\dot{u}$ on $\sigma_{\mathrm{a}}$ for the lower density Carboloy 370 at 3 levels of shock severities.

oxidation effects discussed previously. We do not have independent $K_{\mathrm{IC}}(\dot{u})$ data for Carboloy 370 , apart from two determinations of the room temperature $K_{\mathrm{IC}}$ in an unshocked sample at $8.33 \mu \mathrm{m}$ $\mathrm{sec}^{-1}$ cross-head speed. We may, however, take the $\sigma_{\mathrm{a}}$ values, investigate the fracture surfaces for the flaw from which final fracture took place, and infer $K_{\text {IC }}$ that way. Such results are shown in Fig. 14 , where it is seen that good agreement is obtained with the single unshocked $K_{\text {IC }}$ value at the corresponding cross-head speed. Since, presumably, the flaw sizes produced after a given number of shocks from a given quenching temperature should be the same for all samples, reductions in $\sigma_{\mathrm{a}}$ with rate come from reductions in room temperature $K_{\text {IC }}$ with rate such as given in Fig. 14 .

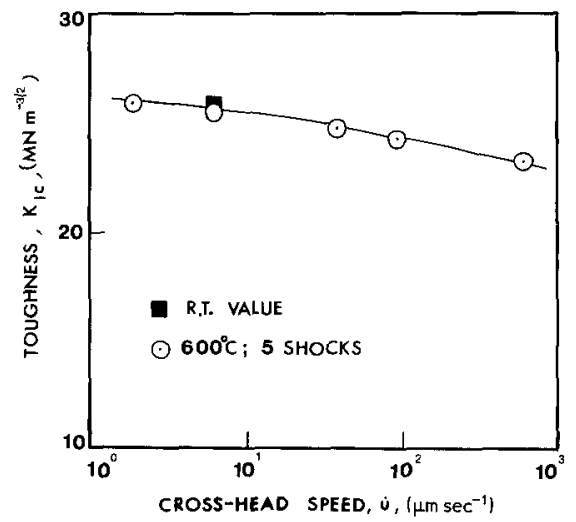

Figure 14 Effects of $\dot{u}$ on $K_{\mathrm{IC}}$ for Carboloy 370 subjected to 5 shocks at $600^{\circ} \mathrm{C}$.

\section{Conclusions}

Those ceramic materials that do not follow the Hasselman model for thermal shock display a gradual reduction in retained after-shock room 
temperature strength, as the severity of the quench is increased. In addition, these materials suffer cumulative damage when subjected to repeated numbers of shocks. This again contrasts with the Hasselman model which suggests that a single shock, of at least the critical quench temperature difference, fully describes the after shock retained strength behaviour. The reason for the departure from Hasselman's model seems to be bound up in reductions in fracture toughness of the ceramics with increasing temperature. Such lower toughnesses allow pre-existing flaws to initiate and grow "sub-critically" during quenches which are much less severe than the Hasselman critical temperature difference predicted from room temperature toughness and strength values. The growth of these flaws is aided by thermal fatigue which accompanies repeated shocking. That the gradual reduction in retained strength is caused principally by increasing flaw sizes is confirmed by the fact that the room temperature fracture toughness of both unshocked and shocked samples is essentially the same.

Oxidation of the Carboloy 370 cutting tool ceramic restored much of its retained strength. This suggests that the dynamic toughness of the oxidized material is greater than the unoxidized material, which, together with the ability of the oxidized layers to relax and expand freely, suggests that the chances of initiating large flaws are less when quenching from temperatures above the oxidation temperature than from below that range.

Rate of testing affects the room temperature results. In general terms, the retained after-shock strength decreases as the crosshead velocity increases because the room temperature fracture toughness decreases with increased rate.

\section{Acknowledgements}

We are most grateful to General Motors Corporation for the grant under which this study was performed. Dr F. Schierloh and his co-workers at the GM Technical Center gave us much guidance, and supplied us with the test material, some of which was specially prepared by the manufacturers concerned; (the results given here are not all necessarily therefore typical of commercial products.) We also would like to thank Mr W. H. Durrant for his help with the experiments and scanning electron microscope investigations.

\section{References}

1. J. NAKAYAMA and M. ISHIZUKA, Amer. Ceram. Soc. Bull. 45 (1966) 666.

2. J. H. AINSWORTH and R. H. HERON, ibid $\mathbf{5 3}$ (1974) 533.

3. D. P. H. HASSElmAN, J. Amer. Ceram. Soc. 52 (1969) 600.

4. Idem, ibid 53 (1970) 490.

5. T. K. GUPTA, ibid. 55 (1972) 249.

6. C. M. CHENG, J. Amer. Rocket Soc. 21 (1951) 147.

7. S. S. MANSON, N.A.C.A. Technical Note 2933 , July 1953.

8. G. R. IRWIN, Proceedings 7th Sagamore Ordnance, Material Research Conference (1960).

9. C. GURNEY, Y. W. MAI and R. C. OWEN, Proc. Roy. Soc. London A340 (1974) 213.

10. A. G. ATKINS, Int. J. Prod. Res. 12 (1974) 263.

11. Y. W. MAI and A. G. ATKINS, Amer. Ceram. Soc. Bull. 54 (1975) 593.

12. R. W. DAVIDGE and G. TAPPIN, J. Mater. Sci. 3 (1968) 165.

13. T. K. GUPTA, J. Amer. Ceram. Soc. 55 (1972) 429.

14. J. A. COPPOLA, D. A. KROHN and D. P. H. HASSELMAN, ibid 55 (1972) 481.

15. B. E. BERTSCH, D. R. LARSON and D. P. H. HASSELMAN, ibid 57 (1974) 135.

16. C. GURNEY and Y. W. MAI, Eng. Fract. Mech. 4, (1972) 853 .

17. Y. W. MAI and A. G. ATKINS, General Motors Technical Rept., September (1974).

18. C. GURNEY and J. HUNT, Proc. Roy. Soc. London A299 (1967) 508.

19. C. GURNEY and K. M. NGAN, ibid A325 (1971) 207.

20. J. E. SRAWLEY and B. GROSS, ASTM, Special Technical Publications No. 410 (1966).

21. N. INGELSTROM and N. NORDBERG, Eng. Fract. Mech. 6 (1974) 597.

22. P. KENNY, Powder Met. 14 (1971) 22.

23. F. F. LANGE, Scientific Paper 73-9D4-FORAM-P1, January 2 (1973).

24. H. G. TATTERSALI and G. TAPpIN, $J$. Mater. Sci 1 (1966) 296.

25. JunN Nakayama, J. Amer. Ceram. Soc. 48 (1970) 583.

26. J. A. COPPOLA, R. C. BRADT, D. W. RICHERSON and R. A. Alliegro, Amer. Ceram. Soc. Bull. $\mathbf{5 1}$ (1972) 847 .

27. L. A. SIMPSON, J. Amer. Ceram. Soc. 56 (1973) 610.

28. A. T. JONES, Engr. Fract. Mech. 6 (1974) 435.

Received 21 March and accepted 21 April 1975. 